\title{
In response to fluid resuscitation with lactated Ringer's solution vs. normal saline in acute pancreatitis: A triple-blind, randomized, controlled trial
}

United European Gastroenterology Journal 2018, Vol. 6(3) 480-481 (C) Author(s) 2018 Reprints and permissions: sagepub.co.uk/journalsPermissions.nav DOI: $10.1177 / 2050640617753281$ journals.sagepub.com/home/ueg @SAGE

\section{Bernardo Calamo-Guzman, Luis De Vinatea-Serrano and Alejandro Piscoya}

We have read the article by de-Madaria et al. titled "Fluid resuscitation with lactated Ringer's solution vs. normal saline in acute pancreatitis: A triple-blind, randomized, controlled trial," and after discussing all the topics about it we have some contributions to the discussion. We agree with the investigators that a larger sample size is needed to give real results about the controversy of normal saline (NS) solution vs. lactated Ringer's (LR) solution used in the fluid resuscitation of patients with acute pancreatitis (AP); however, we are not sure whether it would be feasible because of resource constrains. On the other hand, de-Madaria et al. mention that $\mathrm{C}$-reactive protein (CRP) is a "good surrogate" pancreatic inflammatory marker and gave some references that have multiple issues that need to be pointed out.

First of all, the references are more than a decade old and give only weak conclusions about the use of CRP. In one reference, the authors said CRP seems to be a good severity predictor only if it is in high serum concentrations and helps to differentiate mild from severe disease only at the end of the first week after the beginning of symptoms. ${ }^{1}$ Also, Puolakkainen et al. mentioned that the high increase in CRP was significant enough $(p<0.001)$ to classify the severity of the acute pancreatitis; however, as we said before, this reference is 30 years old and is probably too old to be used to sustain the application of CRP in the current study. ${ }^{2}$ And Mäkelä et al. support the use of CRP as an inflammatory marker for predicting intensive care unit (ICU) length of stay and hospital mortality. In this article, the investigators measured CRP before ICU admission; so, in fact, they did not use it for the clinical evolution of the disease. ${ }^{3}$

The last guideline from the Japanese Society of Hepato-Biliary-Pancreatic Surgery, published in 2015, did not support the use of CRP as an inflammatory marker as it did in $2006 .{ }^{4}$ The guideline says that CRP could be used for the prognosis of a patient's condition only together with other severity prognostic markers such as $\mathrm{PaO}_{2} \leq 60 \mathrm{mmHg}$, creatinine depuration $\geq 2.0 \mathrm{mg} / \mathrm{dl}$, and platelet count $\leq 100,000 / \mathrm{mm}^{3}$. $^{5}$

Some recent studies prove that the use of CRP as an inflammatory marker doesn't have a significant positive likelihood ratio (LR) of 1.58 (using the values of sensitivity and specificity of the study cited, $100 \%$ and $36.8 \%$ each, respectively). ${ }^{6}$ Moreover, in the last diagnostic review by the Cochrane Collaboration, the authors explained that all the studies that were undertaken about the diagnostic development and accuracy of CRP in acute pancreatitis weren't strong enough and more research has to be conducted in the future on the implementation of these serum inflammatory markers (most of the LRs in this review weren't very strong or did not suggest good development). ${ }^{7}$

In conclusion, we do think this clinical trial is an interesting study that compares two different options for the hydration treatment of acute pancreatitis; however, the employment of CRP might be not so accurate as a good surrogate maker for AP during the study.

\section{References}

1. Mayer AD, McMahon $\mathrm{MJ}$, Bowen $\mathrm{M}$, et al. $\mathrm{C}$ reactive protein: An aid to assessment and monitoring of acute pancreatitis. J Clin Pathol 1984; 37: 207-211.

2. Puolakkainen P, Valtonen V, Paananen A, et al. C-reactive protein (CRP) and serum phospholipase A2 in the assessment of the severity of acute pancreatitis. Gut 1987; 28: 764-771.

3. Mäkelä JT, Eila H, Kiviniemi H, et al. Computed tomography severity index and $\mathrm{C}$-reactive protein values predicting mortality in emergency and intensive care units for

Escuela de Medicina, Universidad Peruana de Ciencias Aplicadas, Lima, Peru

Corresponding author:

Luis De Vinatea-Serrano, Escuela de Medicina, Universidad Peruana de Ciencias Aplicadas, Calle Miguel Soto Valle, 112 Lima, Lima, Peru.

Email: Luisdevinatea@outlook.com 
patients with severe acute pancreatitis. Am J Surg 2007; 194: 30-34.

4. Hirota M, Takada T, Kawarada Y, et al. JPN Guidelines for the management of acute pancreatitis: Severity assessment of acute pancreatitis. J Hepatobiliary Pancreat Surg 2006; 13: 33-41.

5. Yokoe M, Takada T, Mayumi T, et al. Japanese guidelines for the management of acute pancreatitis: Japanese Guidelines 2015. J Hepatobiliary Pancreat Sci 2015; 22: 405-432.
6. Cardoso FS, Ricardo LB, Oliveira AM, et al. C-reactive protein at 24 hours after hospital admission may have relevant prognostic accuracy in acute pancreatitis: A retrospective cohort study. GE Port J Gastroenterol 2015; 22: 198-203.

7. Komolafe O, Pereira SP, Davidson BR, et al. Serum $\mathrm{C}$-reactive protein, procalcitonin, and lactate dehydrogenase for the diagnosis of pancreatic necrosis. Cochrane Database Syst Rev 2017; 4: CD012645. 